\title{
Diálogo con Kohut en el encuentro terapéutico. Una inmersión necesaria ${ }^{1}$
}

\author{
Ignacio Blasco Barrientos ${ }^{2}$ \\ $I P R$, Madrid
}

\begin{abstract}
Este trabajo es fruto de las reflexiones que la lectura de Kohut ha suscitado en mi desarrollo profesional. Acompañándome a lo largo del tratamiento de una paciente, respondiendo a mis dudas y sosteniéndome en momentos difíciles. Utilizando varias de las obras más potentes de Kohut y las revisiones de otros grandes pensadores, intento alternar fragmentos de su base teórica junto con viñetas clínicas y reflexiones personales.
\end{abstract}

Palabras clave: Kohut, Psicoanálisis relacional, objeto del self, Self, Psicología del Self, Inmersión empática, Transferencia, Ipseidad.

This work born as a result of the reflections that Kohut's reading has aroused in my professional development. Accompanying me throughout the treatment of a patient, responding to my doubts and holding me in difficult times. Using several of the most powerful works of Kohut and other great thinkers reviews, try alternating fragments of its theoretical basis along with clinical vignettes and personal reflections.

Key Words: Kohut, Relational psychoanalysis, selfobject, self, self psychology, transference, empathy inmersion, ipseity.

English Title: Dialogue with Kohut at the therapeutic meeting. A necessary inmersion.

\section{Cita bibliográfica / Reference citation:}

Blasco Barrientos, I. (2017). Diálogo con Kohut en el encuentro terapéutico. Una inmersión necesaria. Clínica e Investigación Relacional, 11 (2): 387-400. [ISSN 1988-2939] [Recuperado de www.ceir.info ] DOI: 10.21110/19882939.2017.110212

1 Este trabajo obtuvo el primer Premio de la VI EDICIÓN DEL CERTAMEN DE TRABAJOS SOBRE EL DEVENIR PSICOTERAPEUTA (2016) convocado por el Instituto de psicoterapia relacional. 2 Psicoterapeuta individual y de grupo, miembro de IPR. blascoipsi@gmail.com 
Las aportaciones de Heinz Kohut al psicoanálisis fueron elementales para la posterior apertura de la clínica a nuevas formas y modos de entender la psicoterapia. El espacio terapéutico, el enfoque del profesional y el cómo pensar sobre lo que ocurre en la relación paciente - analista han evolucionado gracias a Kohut entre otros grandes profesionales y pensadores. Quizás por su estilo particular consiguió agitar el avispero del dogmatismo ortodoxo de la época desde dentro, influyendo de manera definitiva en colegas que aún leyendo con distancia y cierto vértigo las ideas de Kohut fueron poco a poco seduciéndoles no sólo por la riqueza del contenido teórico sino por cómo sus experiencias en consulta cobraban un significado diferente.

Entiendo que esta profesión siempre ha sido un constante balanceo (poner en equilibrio) entre la inspiración de toda la producción teórica y la vivencia íntima del espacio terapéutico junto a los pacientes.

En este intento de equilibrar ambos campos puede haber importantes desconexiones o incertidumbres donde marearse o perderse siendo esto una situación a veces angustiosa. En cambio, en otras ocasiones, el equilibrio es perfecto y el balanceo se convierte en un movimiento dulce donde de alguna forma todo parece encajar.

Durante el último año los mareos e incertidumbres han estado más presentes de lo que creo recordar dentro de mi ejercicio profesional; Incertidumbres y vértigos en su mayoría tolerables que de alguna forma provocan interrogantes respecto a uno mismo frente al otro. Un otro dañado o perdido que demanda consciente e inconscientemente un abanico de recursos que no siempre puedes desplegar o no éstas en momento de hacerlo. Muchas veces el paciente asume erróneamente que somos casi como cirujanos, que no vacilamos. Que el error o la duda no forman parte de nosotros, en ocasiones esta creencia puede venir de nosotros mismos y afirmo con rotundidad que este es un terreno espinoso.

Quiero creer que esto es una sensación compartida por bastantes colegas, pero sólo esta idea no basta para desenredar este nudo. Sin duda alguna, el trabajo personal, las supervisiones y la inmersión en la teoría de grandes pensadores son herramientas fundamentales para sostenernos ante estas sensaciones. Es en este punto donde Heinz Kohut en algún momento que soy incapaz de ubicar en el tiempo comenzó a aparecer en mi mente, su lectura se convirtió en un diálogo y a día de hoy es una figura fundamental en ciertos espacios subjetivos e intersubjetivos dentro de mí. 


\section{Kohut exploró la fenomenología de la ipseidad . . .}

Frase sacada del libro "Más allá de Freud" (Mitchell). Imagino que es una frase que he leído varias veces pasando inadvertida hasta que dejó de hacerlo. La ipseidad es definida dentro del marco filosófico como asociada a la idea de sí mismo, pero haciendo contrapunto de la noción de mismidad la cual hace referencia a la unicidad del ser sin mayor implicación que ser en sí mismo.

Sartre en "El ser y la nada " dice: "La mismidad alude a la dimensión estructural del ser, a lo que perdura a pesar del tiempo, en cambio la ipseidad apunta a la determinación de la esencia de su existir. La ipseidad constituye el circuito que se encuentra entre el ser en si y el ser para si"

Cuando Mitchell dice que Kohut explora la fenomenología de la ipseidad compacta de forma magnífica la esencia de lo que particularmente creo que Kohut pretende trasmitir por lo que fue viviendo en la suma de sus experiencias personales y profesionales. Esta esencia nos remite a una definición más concisa de la ipseidad que dice: "La ipseidad es el reconocimiento de sí mismo en la experiencia". Esta definición alude sin duda alguna a la experiencia subjetiva de uno consigo mismo, a la experiencia de lo vivido y reflexionado. Desde la perspectiva relacional esta experiencia es la brújula que nos guiará hacia los vericuetos de la vida y en consecuencia lo que nos llevará a terapia. Es en el espacio terapéutico donde Kohut llevará a profundo análisis esta idea de reconocer (se) al otro (uno) en la experiencia favoreciendo un espacio intersubjetivo que será la semilla de la psicología del self así como del psicoanálisis relacional. En el camino Kohut irá paulatinamente replanteándose la necesidad de actualizar los cimientos del psicoanálisis clásico imperante; Pilares como el concepto y la función de la pulsión o el manejo de la transferencia y las interpretaciones son pensados por Kohut de tal manera que invita a flexibilizar la rigidez de la escuela psicoanalítica. En este camino tendrá que enfrentarse a múltiples obstáculos y decepciones que sus propios colegas le irán poniendo.

\section{Del hombre culpable al hombre trágico:}

Freud estableció al ser humano como alguien que vive de forma solitaria en una guerra interna donde las batallas que se libran en su psique son fruto de pulsiones primitivas frente a estándares sociales y civilizados de comportamiento.

El niño en sus primeras experiencias es un ser omnipotente y sus vivencias son mágicas. Según va desarrollándose y avanzando por las diferentes fases su gratificación es autodirigida, poco a poco se va viendo frustrado en este terreno y su energía libidinal 
cambia de dirección, se externaliza hacia sus progenitores (la libido narcisista se transforma en libido objetal). Cuando la fase edípica comienza a asomar el niño vuelve a la frustración, esta vez por las fantasías edípicas que ha de ir abandonando en el transcurso de las experiencias vitales dentro del contexto de apego con los padres. Estas fantasías edípicas tienen un fuerte componente sexual que indudablemente nos llevarán al sentimiento de culpa. Es aquí donde el niño establece las bases que de adulto le harán librar esas batallas que antes he mencionado de una forma más saludable o por contra, de forma patológica. Esta culpa será uno de los principales afectos del conflicto pulsional clásico, afirma Kohut.

En cambio, él adoptará una visión muy distinta de este proceso. Kohut ve la patología no como fruto de las batallas internas que Freud mencionaba sino como la sensación de aislamiento del hombre, analiza el problema del ser humano desde la perspectiva de no disfrutar de lo que se es. Volviendo a la ipseidad, Kohut afirma que el niño debe desarrollarse en un entorno que le otorgue las experiencias necesarias no sólo para seguir siendo un ser humano sino para sentirse como tal, sentirse en conexión con el entorno, sentirse productivo, activo o creativo y no sólo serlo.

Si la persona no se siente así, si su contexto de apego no ha facilitado la valía personal, no ha fomentado la creatividad o no se ha nutrido de experiencias relacionales sanas y recíprocas el ser humano se abandona, se resquebraja, se avergüenza y como no, aparece la tragedia. Es aquí donde Kohut contrapone la idea de hombre culpable propio del psicoanálisis clásico frente al hombre trágico donde predomina el sentimiento de vergüenza y dice: "Uno se siente culpable de lo que hace, y se avergüenza de lo que es".

\section{Hacia un entorno donde sólo se es, sin ser par sí.}

Esto me hace plantearme cómo ha de ser nacer en un contexto vacío de experiencias donde afirmar la valía personal, un entorno donde los mensajes son inconexos y donde la creatividad, el juego y las necesidades son frustradas aleatoriamente, sin coherencia alguna.

Leticia es una chica de 28 años, sus recuerdos infantiles son muy vagos hasta casi los ocho. Recuerda en su hogar a varios perros con los que jugaba en su infancia, cuando dice varios no se refiere a todos a la vez sino la consecución de diferentes animales en momentos temporales distintos. Su recuerdo de jugar con ellos se desvanece con celeridad dejando paso a la sensación de vacío y tristeza fruto de la desaparición de estos, por algún motivo no se quedaban en casa, por alguna extraña razón estos perros eran devueltos o abandonados. 
Leticia relata fuertes sentimientos de agresividad contra si misma y contra otros desde muy joven, casi desde que tiene recuerdos de sí misma. Esta agresividad causaba problemas en casa y en el colegio. Poco a poco va identificando que esa agresividad no solo salía de ella, recuerda momentos donde era golpeada por su madre, tortas, tirones de pelo aleatorios o pellizcos. Nunca había ensañamiento ni se alargaban en el tiempo, pero no eran coherentes a lo que había hecho y de alguna forma no se podía predecir cuándo llegaría el siguiente. Golpes físicos que silenciosamente provocaban heridas emocionales.

Este breve ejemplo nos sitúa en un entorno de desarrollo espinoso, no sólo los golpes eran incoherentes, también la comunicación. Los mensajes eran ambivalentes, los éxitos escolares podían ser correspondidos con exageradas felicitaciones y alegrías o con un escueto "Es tú deber, es lo que tienes que hacer". Fracasos había pocos, Leticia disfrutaba del colegio y de las clases, recuerda ser excesivamente social y tener muchas amigas, de alguna manera se nutría de un entorno distinto al de su casa. Pero siempre tenía que volver, y en casa las cosas seguían igual por lo que tal como relata la propia Leticia a los once años algo pasó en su cabeza, un clic cambio para siempre sus forma percibir las cosas, cambió la forma de relacionarse, comenzó un repliegue que durante los siguientes años le haría transitar por lugares muy oscuros, por sensaciones de fragmentación y agresividad siempre acompañados por una intensa angustia.

Muy brevemente he propuesto una viñeta donde encontramos que las vivencias infantiles de esta chica no fueron el espacio ideal; ni de lejos fue un espacio suficientemente bueno. Fue un espacio de tensión, un espacio donde no poder predecir lo que va a pasar. Esto produce un estado de alerta constante, la psique se adapta a lo que pueda venir sin saber cuándo ni cómo lo hará, el desgaste está servido. ¿Cómo puede un niño fantasear, evadirse, en sus juegos en este estado de alerta?. En un principio se puede calificar esto como un infierno, como el horror más absoluto vivido, mi posición al principio fue esa, observar desde la distancia el relato de sucesos muy perturbadores. Poco a poco fui dilucidando que aun siendo horrorosos eran sus sucesos, era su vida, era su experiencia. En su psique ese hogar era su hogar, era su espacio de desarrollo, era su entorno de vida. Tildar de horror ese espacio era una perspectiva externa, una perspectiva propia fruto de mis vivencias y fruto de la inevitable comparación de mis experiencias tempranas con las de quien tengo delante. En definitiva, era un choque al que debía acomodarme. No sólo debía seguir escuchando, sentía la necesidad de recolocar mi actitud, mi perspectiva o mi atención, en definitiva, debía arremangarme y hacer una inmersión completa en lo que ahí estaba pasando. 


\section{Inmersión empática como acceso a la subjetividad y vivencia del otro.}

Kohut comenzó a mirar desde otro punto de vista las experiencias tempranas. La vitalidad y exuberancia infantil en comparación con la apatía, rigidez y gris vida de muchos adultos le llevó a pensar en qué ocurría en ese espacio intermedio. ¿dónde se perdía la vitalidad infantil? ¿Dónde desaparecía esa espontaneidad creativa?.

Ante estas preguntas no encontró respuesta por el camino que el psicoanálisis clásico proponía en la relación terapéutica. No encontró un acceso sostenible mediante las interpretaciones y frialdad analítica clásica.

Por esta razón decidió enfocar la empatía desde otras perspectivas, cambiar la óptica utilizada para definir y trabajar empáticamente. Kohut explicita en todo momento que la empatía es la actividad que define el campo del psicoanálisis y que siempre ha estado ahí, él niega en todo momento que la psicología del self haya introducido una nueva clase de empatía, simplemente propone un enfoque distinto de lo que ahí estaba. Lo que Kohut propuso es el concepto de inmersión empática como una actitud de interés sincero por posicionarse en las vivencias del otro, no cómo uno mismo las viviría sino como el otro pudo vivirlas en ese momento temporal; siendo inevitable el poso de la subjetividad de uno mismo. Esta empresa no es de fácil acceso o resolución, requiere una atención completa y un esfuerzo por entender sin miedo a volver a peguntar o indagar de forma exhaustiva, por eso el término inmersión me parece completamente acertado. Kohut dice que se ha de aceptar la inexactitud y utilizar esta indagación exhaustiva antes de interpretar o confrontar nada. Hay pacientes a los que en ciertas circunstancias sólo les es tolerable el ser escuchados en silencio.

Todas estas palabras cobraron mucho sentido cuando frente a Leticia yo sentía que debía cambiar algo para solucionar no se muy bien qué. Era una necesidad mía más que lo que demandaba el contexto terapéutico por lo que frené esa necesidad de cambiar algo y seguí haciendo lo que ya estaba haciendo y en cierta medida funcionando, escuchar.

Detrás de esa escucha había una comprensión a veces más accesible y otras más enredada. Kohut dedica tiempo a explicar las fases de comprensión - explicación dentro del análisis y dice que en ciertos pacientes la fase de comprensión durante mucho tiempo ha de ser la única vigente.

Tal como he comentado Leticia a los once años nota ese clic, las cosas en casa no cambian ni han cambiado hoy día, pero ella de alguna forma lucha y no se abandona. Supera con gran éxito la escuela y decide comenzar comunicación audiovisual desarrollándose en la parte más creativa de esta. El clic le ha llevado a ser más retraída, ya no es la niña sociable 
y habladora. Se relaciona, pero con distancia, es sentida (y se siente) rara frente a otros. Desde la preadolescencia comienzan a asomar síntomas llamativos, pequeñas agresiones a si misma que a veces no son tan pequeñas. En este proceso de crecimiento y apertura a experiencias nuevas los mensajes de su madre siguen siendo incoherentes y exacerbados. Cuando Leticia se siente más libre y creativa su madre enferma y demanda su atención, al principio le dice que no le deje sola, poco a poco le boicotea para que no vaya a la universidad, pasa a perseguirla y controlar todas sus salidas, le explica que el mundo es un lugar peligroso donde pueden dañarla.... ¿Dónde va a estar mejor que con su madre?. Leticia de alguna manera no sabe si sufre ella o sufre su madre, cuando ella está mal su madre mejora y viceversa. La madre ya no la golpea físicamente pero sí emocionalmente, el estado de alerta se incrementa, en cualquier momento puede aparecer mediante una llamada, mediante un grito o mediante la furiosa entrada en su habitación a cualquier hora del día o de la noche... El sueño desparece, dormir significa relajarse, relajarse significa ser sorprendida aún con más virulencia, la angustia crece, los ataques de ansiedad se incluyen en su día a día.

Los últimos años de carrera vienen marcados emocionalmente por agresiones hacia si misma cada vez mayores, consumos, mala alimentación y cortes en sus brazos y piernas.

Sesión tras sesión, Leticia despertaba en mí sentimientos dolorosos, de difícil digestión, necesitaba tiempo para recomponerme, en ocasiones sentía euforia por la intensidad de sus relatos, otras veces asombro por su capacidad de supervivencia, pero siempre acaba sintiendo una mezcla de rabia y tristeza. Comencé a arremangarme y preguntar todo ante su disposición de contármelo, el contenido era muy doloroso para ella, pero sobre todo era vergonzoso, relatar cómo necesitaba dañarse, como después de hacerlo sentía una profunda culpa y cierta despersonalización era un terreno muy difícil de compartir con alguien. En el momento creí no estar haciendo nada, pero en el diálogo con Kohut fui entendiendo que estaba escuchando y en la medida de lo posible comprendiendo algo que de alguna forma ella captaría. Como he dicho antes, el material era difícil de manejar y en un momento dado se lo hice saber, le expliqué que algunos temas generaban mucha tensión en mí, que se me hacían difíciles, que no sabía cómo abordarlos. Esta intervención fue pensada previamente, pero la sentí como un salto al vacío, no quería que entendiese que me quedaba grande su caso, al fin y al cabo, su vida. De alguna forma era yo el que temía perder el punto de vista, era yo quien el que no quería aceptar que en ocasiones podía perder mi sitio, en definitiva, era yo el que estaba afirmando lo grande que me quedaba ese caso. De alguna manera esa fase de comprensión a la que Kohut hace referencia cobró sentido, no sólo en la comprensión hacia ella, sino hacia lo que ella hacia que surgiese de mí. expresa. Este material es para uso científico y profesional exclusivamente y puede contener información clínica sensible. Los editores no se responsabilizan de los contenidos de los autores. Dirigir las consultas sobre derechos y autorizaciones a ceir@psicoterapiarelacional.es 
Ante mi intervención su respuesta fue realmente tranquilizadora y en cierta medida creo que abrió un campo diferente, un diálogo terapéutico distinto. De alguna forma me comprendió, de una forma muy natural y espontánea me explicó que era normal, que nunca había hablado así de esos episodios con nadie y que entendía que me sintiese así, acto seguido afirmó que yo le venía muy bien. Esta respuesta, además de tranquilizarme me recolocó y en definitiva me hizo reafirmarme en el compromiso terapéutico que tenía con ella.

Una de las apreciaciones de Kohut hacia la interpretación transferencial del psicoanálisis clásico es que en ocasiones el intento de encajar la teoría al paciente que se tiene delante lleva a interpretaciones de difícil manejo o en momentos inadecuados, favoreciendo esto la dimensión repetitiva de la transferencia y sus consecuentes resistencias. En cambio, cuando el diálogo analítico permite esclarecer este conflicto entre la subjetividad del paciente y la subjetividad del analista la dimensión repetitiva de la transferencia pierde protagonismo y se va desplegando la dimensión de selfobject de la transferencia. De tal forma que el paciente puede ir mostrando aquellas necesidades del selfobject que habían quedado frustradas en el pasado. (Introducción a la psicología del self, Ramón Riera, 2002)

Kohut concluye que el niño necesita crecer en un entorno sano donde el self evolucione con experiencias selfobject específicas y hace un paralelismo con la relación terapéutica y la transferencia. Así el niño herido por un entorno perturbador no ha tenido esas experiencias selfobject porque sus objetos self no han estado disponibles o preparados para dárselas. En cambio, en la relación terapéutica se pueden reinstaurar estas experiencias con el selfobject analista. Las diferentes fases temporales del tratamiento, la disponibilidad del analista y las transferencias marcarán en el paciente estas experiencias selfobject que le permitirán sanar o regular mejor sus sentimientos de fragmentación, dolor y vergüenza de ser y sentirse así.

\section{Experiencias necesarias en el desarrollo y en el espacio terapéutico. Hacia una nueva forma de transferencia.}

Kohut en "Análisis del Self" identifica tres experiencias clave para un desarrollo sano.

La primera experiencia exige selfobjects que respondan al sentimiento innato de grandeza del niño, básicamente que se apoyen los estados de ánimo expansivos del niño.

La segunda exige la implicación del niño junto a otras personas poderosas con las que el niño pueda fusionarse como una imagen de calma, infabilidad y omnipotencia. 
La tercera exigiría que el niño viva experiencias con su selfobject que evoquen un sentimiento de parecido esencial entre el niño y ellos mismos, es decir una identificación sana y real.

A partir de estas tres experiencias Kohut plantea en el marco de la transferencia situaciones que puedan reinstaurar en los pacientes las funciones selfobject que de niños fueron frustradas.

El analista ha de cumplir una función especular, a través de la inmersión empática es el analista quien de forma paulatina valida la subjetividad y emociones que el paciente vuelca en la terapia. Esto es sin duda alguna una de las bases dentro de la psicoterapia relacional actual, validar conjuntamente las sensaciones subjetivas de nuestros pacientes.

Ante Leticia en ocasiones me removía por dentro pensar cómo una madre puede jugar ese papel con su hija, no alcanzaba a entender esos relatos infantiles donde constantemente era frustrada la creatividad, el diálogo o la tranquilidad de un sábado por la mañana. Cuando entendí que esa era su vivencia, su hogar y su madre pude empezar a dialogar con ella desde el ¿Cómo se había sentido en esas ocasiones? ¿Cómo vivía ahora el recuerdo de esas situaciones? ¿Hasta dónde cree que podía influir en sus síntomas esta relación tan temprana?. Estos interrogantes fueron respondidos dentro de un entorno terapéutico tranquilo, sin estados de alerta, con escucha y profundo respeto. Entiendo que de alguna forma hablar largo y tendido de esto me hizo comenzar a pensar desde Leticia, comprobando si iba por el buen camino ella me lo confirmaba cuando juntos validábamos nuestras impresiones en el dialogo intersubjetivo. A su vez Kohut dialogaba conmigo y de alguna forma me hizo entender que estaba cumpliendo esa función especular en la medida en que abandonaba mi falta de comprensión y frustración hacia la madre de Leticia y me posicionaba en lo que su experiencia subjetiva había acumulado o disociado emocionalmente.

Kohut identifica otros tipos de transferencia que responden a un buen trabajo terapéutico, la transferencia idealizadora y la transferencia gemelar. La primera es la vivencia del analista como alguien importante en virtud de su conexión con él. La segunda responde el anhelo de sentir una semejanza esencial con el analista, en cuanto a la importancia de su función afirma Kohut.

Ha pasado casi un año desde que Leticia apareció en consulta, venia después de cuatro años de impasse en su vida, cuatro años con ingresos psiquiátricos, profunda angustia, alto consumo de estupefacientes y muchas escenas potencialmente dañinas para cualquier psique. Cuatro años en los que abandonó la carrera justo antes de acabarla y con excelentes notas, donde se especializó en la parte más creativa de la comunicación audiovisual y era 
muy valorada por profesores y compañeros. Su vida social era rica e intensa, a veces demasiado intensa. Todo esto tenía el contrapunto de lo que en casa había vivido y seguía viviendo, el desgaste debió ser absoluto, no pudo más, tenía que enfermar.

Era una ávida lectora, una autodidacta en múltiples terrenos intelectuales, todo eso se había perdido, una de sus principales frustraciones era el no ser capaz de hacer ni la mitad de lo que antes hacía, no sentirse útil, haber tirado todo a la basura, no ser capaz de concentrarse, de fundirse en los libros, de seguir aprendiendo, era extremadamente dura consigo misma y se avergonzaba de lo que había hecho, o dejado de hacer.

A día de hoy, Leticia ha comenzado a estudiar otra vez, tiene ideas de independizarse, le gustaría no sólo acabar la carrera sino hacer alguna otra, el esfuerzo por todo esto es intenso, pero lo sobrelleva. No todo es un camino de rosas, hay grandes retrocesos, hay pinchazos y sobretodo hay un entorno que no se puede cambiar de momento, un entorno que conlleva la repetición de los traumas acumulados, la alerta constante frente a la invasión de su espacio físico y psíquico. Lo que hemos creado conjuntamente es un espacio privado, un espacio donde por fin nadie va a entrar y sobresaltarnos, un espacio de cuidado y respeto, algo nuevo que compartimos y desde donde hacer frente a lo que pueda venir. Quiero creer que ella me respeta en la medida en que soy importante en su vida, pero no creo que hayamos entrado en la transferencia idealizadora ni en la gemelar. Hay un trabajo hecho, pero queda mucho más por hacer, el camino es largo.

En los últimos meses me he visto en diferentes sesiones magnificando a Leticia, sobrevalorando lo que hace y sintiéndome profundamente orgulloso de ella, de alguna forma se lo iba trasmitiendo y no era del todo bien recibido, tampoco negaba o confrontaba, pero no estaba cómoda ante esas aportaciones mías, evidentemente pensé mucho en ello, me cuidé de no caer en la alabanza gratuita o motivación vacía. Quería pensar que no era así y me esforcé por ver que estaba ocurriendo.

Kohut volvió a dialogar conmigo y llenar cierto vacío. En ¿Cómo cura el análisis? dice:

"En general, se nos ha enseñado a considerar desencaminadas estas actitudes, a entenderlas como manifestaciones de que nuestro juicio sensato ha sido apartado de su recto camino por las emociones. Y los analistas, en particular, han interpretado que su tendencia a valorar a sus pacientes (a sus talentos y logros) más que otras personas que los tratan en su vida cotidiana es una variante contratransferencial, concretamente un ejemplo de una actitud que debe ser dominada y a la postre eliminada por el autoanalisis y la comprensión de la dinámica y genética de tales juicios deformados. No obstante, a mi entender esta actitud posee otra dimensión, tanto en el caso de los padres frente a los hijos como de los analistas frente a los pacientes. Creo que también esta actitud de sobrevaloración es "normal"; ella expresa el eco 
de que como progenitores y terapeutas, funcionamos de acuerdo con nuestro designio, y un analista que la suprime deliberadamente y la reemplaza por una objetividad fría, para adecuarse a la metáfora freudiana del analista como cirujano esta tan desencaminado como la madre "objetiva" de hace medio siglo que se guiaba por los preceptos watsonianos"

Y más adelante continua:

"Tanto los progenitores como los analistas insistirán en que el niño y el paciente, respectivamente se enfrentan a realidades desagradables para ellos, e incluso acepten los límites que a todos nos impone la vida; pero al mismo tiempo reconocerán que cada ser humano tiene derecho a sentirse especial y único, tiene derecho a pensar que su existencia es imposible si no es corroborado por los demás, es especial por sus padres y por los que luego adquieren una significación parental, como objetos / si mismo". (El papel de la empatía en la cura psicoanalítica. Cap 9. Pag 276. Como cura el análisis. Paidos. 1986).

Es evidente que los cimientos relacionales de Leticia no han sido los óptimos, no creo que hayan sido suficientemente buenos en su totalidad, pero sí en ciertas particularidades de sus vínculos ha encontrado espacios donde poder desarrollar aspectos saludables, aspectos que le han convertido en única y especial. Estos espacios no fueron validados conscientemente en su momento, pero de alguna forma hubo alguien que estuvo, al menos mirando hacia ella para hacerla sentir especial. Nunca se lo dijeron, nunca fue explícito, pero algo tuvo que captar para ser la superviviente que hoy día viene a consulta. Nunca dejó de luchar, la lucha a veces fue tan dura que tuvo que enfermar, ella misma se llevaba a límites incomprensibles, se ponía a prueba dañándose, lo que le hacía fuerte también le hundía. Necesitaba sentir mediante el dolor, mediante sus constantes ataques a su cuerpo sentía que de alguna forma estaba viva, nunca llegó a intentar dañarse para desaparecer, siempre había un control fruto de esa supervivencia innata, fruto de ese núcleo del self que necesita vivir y sentir. Esto es lo que a mí en ocasiones llega a emocionarme, no pretendo dejar nunca de sentir admiración por cómo los pacientes son a pesar de sus contextos, vínculos e historias traumáticas. No pretendo dejar de hacerlo porque como a Kohut le debió pasar, me ilusiona y apasiona este encuentro intersubjetivo que en ocasiones se da en terapia. Reivindico la pasión, energía y alegría que Kohut se encarga de desplegar en sus escritos, una forma de humanizar la rigidez científica en momentos convulsos, un hombre que con suma valentía sacrificó su estatus por servir a unas ideas que en su intimidad iba confirmando y afianzando, un pensador capaz de regalarnos una obra como "Los dos análisis del Sr. Z" con lo que eso implicaría en su fuero interno. 


\section{Ulises como contra-magia a Edipo.}

Esta creencia profunda en la humanidad, esta idea que Kohut fue desarrollando con los años es defendida muy elegantemente ante muchos colegas en el cincuenta aniversario de la sociedad psicoanalítica de Chicago. Conferencia titulada "Introspección, empatía y el semicírculo de la salud mental" que leyó su hijo a los asistentes. En su intento de otorgar nuevas perspectivas al psicoanálisis Kohut pone sobre la mesa el mito de Edipo rey planteando si es necesario seguir tomándolo como mantra. En un primer momento plantea cómo es posible que nadie haya escrito o haya señalado que Edipo era un niño rechazado, que al fin y al cabo ese dato tendría que ser una característica crucial en el posterior desarrollo de Edipo. Fue abandonado y aún rescatado por unos sustitutos paternos tuvo que permanecer en él ese rechazo original.

Ante el mito de Edipo, Kohut rescata la historia de Ulises, el cual se encontraba con su recién nacido Telémaco y su mujer cuando unos emisarios fueron a buscarlo para ir a combatir a Troya. Ulises fingió estar loco para no ir a la guerra y los emisarios lo encontraron con un cómico sombrero, arando con un buey y un asno uncidos juntos y echando sal sin cuidado alguno al terreno. El emisario Palámedes sospechó del engaño y colocó al bebe Telémaco en el camino donde Ulises araba, este inmediatamente trazó un semicírculo para salvar a su hijo y acabó confesando que estaba fingiendo.

La esencia de contraponer a Edipo y Ulises es que al fin y al cabo los progenitores aman por encima de todo a sus hijos, que lo "normal" es el apoyo a las generaciones venideras y no el odio, competitividad y seducción que el mito de Edipo pretende establecer. No sólo eso, Kohut reivindica que el núcleo del Self más profundo es el que a todos nos lleva a trazar el semicírculo que Ulises trazó y que los impulsos agresivos o la patología es fruto de capas más externas del Self que fueron creciendo en base a respuestas defectuosas de selfobjects que en la crianza no ofrecieron lo óptimo a sus progenitores; Pero en el fondo y con el trabajo analítico profundo se pueden ir sorteando esas capas defectuosas para llegar a ese núcleo humano y reivindicativo de la salud mental, asumiendo que este trabajo con ciertos pacientes siempre sera un difícil camino pero que si se llega con alguno merecerá la pena el intento con todos los demás.

No volveré a repetir los defectos de los selfobjects que Leticia ha tenido y tiene, pero es evidente que en ella existe un núcleo saludable y protector hacia ella misma. En algún momento, por remoto que sea estoy convencido de que hubo una conexión cariñosa con esos selfobjects, en algún punto alejado de la conciencia se cimentó ese núcleo del que Kohut habla. No sé hacia donde iremos Leticia y yo pero gracias a Kohut he podido entender lo que ya hemos caminado y lo mucho que queda por hacer; Antes me planteaba 
donde estaban los objetivos, con qué techo podía encontrarme en el tratamiento de Leticia, ahora esto ocupa poco tiempo en mi mente, creo que hay una base co-construida donde poder dialogar intersubjetivamente ante los conflictos que surjan en su vida y los que surjan entre nosotros, y ahí estará la clave del cambio; como antes he dicho aún no he vivido la transferencia idealizadora o gemelar pero de lo que estoy seguro es de que he sentido que es única, que no hay nadie como ella. Que seguiré asombrándome de su valor y validando sus emociones. $Y$ es en este punto en el cual Kohut me dejó claro que es un buen camino por el que transitar.

Kohut afirmó rotundamente que el psicoanálisis había llegado a un punto donde debía dejar de estudiar a Freud para pasar a estudiar al ser humano. Muchas veces mal interpretado por el ataque al padre creo que hasta en esa frase lo que Kohut trasmite es un profundo respeto por Freud. Pero entiende la necesidad de abrir espacios distintos en el pensar de los profesionales, entiende que la potencialidad de humanizar la relación terapéutica es infinita y lo más importante de todo: El protagonista en todo esto es el paciente que acude a nuestra consulta, es quién en su sufrimiento tiene el valor de acudir semanalmente a exponerse frente a nosotros, poner en valor esto está por encima de muchas teorías o enfoques y es aquí donde paradójicamente las teorías de Kohut me han ayudado con Leticia y conmigo mismo, es en su teoría donde despliega ese respeto y cuidado a la subjetividad de quien tiene delante.

Erikson dice que Freud afirmó que la normalidad se define como la capacidad de amar y trabajar. Kohut se da cuenta de que faltaba un elemento crucial y añadió que la normalidad es la capacidad de sentirse feliz y orgulloso en esas capacidades de amar y trabajar. Sencillo pero claro, muy claro.

\section{REFERENCIAS}

Armengol, R. (2002). La técnica de Kohut y el psicoanálisis del futuro, En Los dos análisis del Sr. Z., Heinz Kohut (pp. 189-221). Barcelona: Herder.

Kohut, H. (2002). Introspección, empatía y el semicírculo de la salud mental. En Los dos análisis del Sr. Z., Heinz Kohut (pp. 149-186). Barcelona: Herder.

Kohut, H. (1977). Análisis del self. El tratamiento psicoanalítico de los trastornos narcisistas de la personalidad. Buenos Aires: Amorrortu

Kohut, H. (1986). Papel de la empatía en la cura psicoanalítica. Cap 9 (pp. 251-277), en ¿Cómo cura el análisis?, Buenos Aires: Paidos.

Kohut, H. (2002). Los dos análisis del Sr. Z. Barcelona: Herder 
Mitchell, S y Black, M. (2004). Más allá de Freud. Herder. Barcelona.

Riera, R . (2002). Introducción a la Psicología del Self. En Los dos análisis del Sr. Z., Heinz Kohut (pp. 17-90) Barcelona: Herder.

Serra U. J.K. (2015). Tensiones teóricas en relación a Kohut, una revisión crítica. Clínica e investigación relacional, 9 (1): 206-230.

Original recibido con fecha: 23/3/2017 Revisado: 28/3/2017 Aceptado: 30/06/2017 